\title{
Experimental study of a hybrid mooring system
}

\author{
Chunyan $\mathrm{Ji}^{\mathrm{a}}$, Zhiming Yuan ${ }^{* \mathrm{~b}}$ \\ School of Naval Architecture \& Ocean Engineering, Jiangsu University of Science and Technology, Zhenjiang 212003, \\ China \\ Department of Naval Architecture \& Marine Engineering, University of Strathclyde, \\ 100 Montrose Street, Glasgow G4 OLZ, UK \\ e-mail:zhiming.yuan@strath.ac.uk
}

\begin{abstract}
Mooring systems are essential to the floating structures including offshore platforms, wave energy converters (WEC) and floating breakwaters. As floating structures propagate towards deeper waters, the design of the mooring systems needs to be revamped. In the present study, a new hybrid mooring system has been proposed. A series of weights and buoys are arranged to the different segments of each mooring line in order to improve the motion performance of the platform and eliminate the vertical forces at the lower end of the mooring lines. A series of experiments have been carried out at CSSRC wave basin for a semi-submersible platform moored by the mooring lines with or without the weights and buoys. The mooring lines' tension and 6-DOF motions of the platform were measured. Discussions have been made on non-linear motion responses of the semisubmersible and non-linear mooring line tension responses for various mooring conditions.
\end{abstract}

Key words: hybrid mooring system; mooring lines; clump weights; buoys

\section{INTRODUCTION}

As an essential part of the floating mooring structures, the mooring system has been a challenging research topic, especially when the floating structures move towards deeper waters. There are mainly two categories of mooring systems based on their configurations. The first category, most commonly preferred in shallow water, is the catenary mooring system $[1,2]$. It gets its name from the shape of the free hanging line as its geometrical shape changes due to vessel motions. The weight of the chain or shackles comprising the catenary line generates a restoring force against the motions of the structure. At the seabed, the mooring line lies horizontally; thus, a drag embedment anchor can be utilized. However, the mooring line has to be longer than the water depth. Increasing the length of the mooring line also increases its weight. As the water depth increases, the increasing weight of the mooring lines reduces the working payload of the vessel. Consequently, conventional catenary systems become less and less economical with increasing water depth. For this reason a different method has been developed, called taut-leg mooring system $[3,4]$. The lines are connected to the floating structures and go in a fairly straight line to the bottom. This is only possible with light lines, therefore modern polyester lines are needed to achieve this. These lines have a large axial resistance and good fatigue properties. When the platform drifts horizontally with wind or current, the lines stretch and this sets up an opposing force. The lines usually come in at a 30 to 45 degree angle on the seabed where they meet the anchor, which is loaded vertically. Therefore, suction piles must be used for deep water taut mooring lines to resist the vertical forces. Suction piles can be used in sand, clay and mud soils, but not gravel, as water can flow through the ground during installation, making suction difficult. And also suction piles are usually forbidden to be adopted in reefs for the environmental protection. Furthermore, the installation and maintenance of suction piles is very expensive.

To overcome the shortcomings of these two mooring systems, some component mooring lines with additional sinkers and buoys are proposed. Smith et al. [5] used catenary equations to solve a three component mooring made up of two lines, connected at a point buoy or sinker where water depth and fairlead tension were given. Vicente et al. [6] investigated different mooring configurations with slack chain mooring lines of a floating point absorber with or without additional sinkers or floaters. It was found that the different 
arrangement of the buoys and weights would bring significant differences in terms of average and maximum tensions on the mooring cables. Hong et al. [7] carried out an experimental study for a compliant mooring system keeping a floating OWC device. The compliant buoy mooring system consists of four mooring systems, each of which has a buoy connected to horizontal and vertical mooring lines. However, this wave energy device was damaged by mooring line failure during a severe storm. This study has been made to clarify the mechanism of mooring line failure for future improvements in mooring line design.

These studies have led to some progress in the mooring line design. However, these improvements are only based on connecting a single sinker or a single buoy to the mooring lines, and their benefits are limited. A systematic study about the influence of the weights and buoys needs to be conducted. Ji et al. [8] proposed a new mooring system integrating both catenary and taut mooring systems. In their study, some lumped masses were applied to the lower end of the taut lines at uniform intervals. Thus, the mooring lines would lie horizontal at the seabed, which leaves only horizontal forces at the lower ends of the mooring lines. It is a great improvement, since the requirements for the seabed soil properties could be lowered and the installation and maintenance costs would be reduced. They carried out a numerical simulation for a semi-submersible platform with this hybrid mooring system. The results showed that vessel motions and mooring line tensions could be reduced greatly when the proposed mooring system is used. It also has been demonstrated by Yuan et al. [9] that this hybrid mooring system is suitable for a wide range of water depth. But, as pointed out by the author, the maximum tension of the proposed mooring lines turned out to be greater than the conventional taut mooring lines when the water depth exceeds $1000 \mathrm{~m}$.

In the present study, based on the previous numerical simulation results by Yuan et al. [8, 9], a series of model tests have been carried out at China Ship Scientific Research Center (CSSRC) wave basin for a semi-submersible platform moored by the mooring lines with or without the weights. Furthermore, some improvements are made by adding some buoys to the previous mooring lines in proper position, which is expected to reduce the maximum tension on the mooring lines. Mooring line forces and 6-DOF motions of the model have been measured. Comparisons between the taut mooring system, the hybrid mooring system with weights and the hybrid mooring system with both weights and buoys are discussed.

\section{HYBRID MOORING SYSTEMS}

The design of the present hybrid mooring lines is based on the configuration of the taut mooring lines. It can be seen from Fig. 1 that when taut mooring lines are applied as the mooring system, the lines go in a fairly straight line to the anchor. The angle between the mooring line and the anchor leads to the existence of a significant vertical force at the anchor, necessitating a strong holding capacity of the anchor. In order to eliminate the vertical component of the mooring force at the lower end of the mooring line, a series of weights have been attached at the line's lower end, which is shown in Fig. 2. And couples of these mooring lines with weights will constitute a hybrid system, which has been called hybrid mooring system with weights (HMSW). It can be seen from Fig. 2 that the weights are attached to the lines at uniform intervals and the sizes of these weights diminish gradually when moving from the sea bottom upwards. Therefore, the lower end of each line is expected to act as a catenary if the weights are arranged properly. When the lines are subject to the maximum tension, it should be designed to fulfill the following condition: The weights next to the anchor point $\left(m_{1}\right)$ should never be lifted from the sea floor. Thus, it can be guaranteed that there is no vertical force at the lower end of the mooring line since it is counteracted by a natural weight. When the tension decreases, the weights will be supported by the sea floor, thereby alleviating the tension at the fairlead. However, in the numerical simulation [9], line tensions could be increased under the gravity of the weights. In order to lower the line tension, a buoy is attached to each mooring line, shown in Fig. 3. Couples of mooring lines with weights and buoys constitute a new hybrid system, which has been called hybrid mooring system with weights and buoys (HMSWB). The buoyancy of these buoys will counteract some of the gravitational forces, which is expected to reduce the tension on each mooring line. Meanwhile, the included angle between the water line and the mooring line could also be decreased. Thus, the horizontal restoring force 
provided by the line can be increased while the restoring forces in vertical direction will be reduced. With the same principle as the HMSW, the proper arrangement of the weights in HMSWB should also guarantee a horizontal alignment of the mooring line near the sea bed.

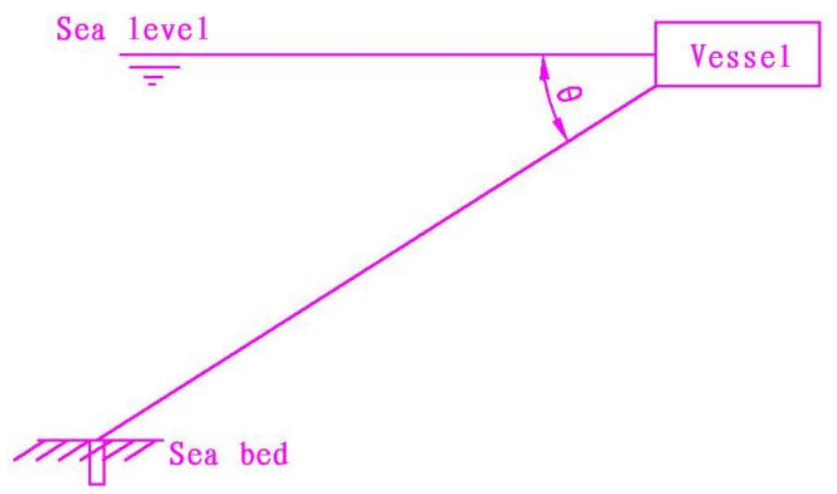

Fig. 1 Taut mooring line (TML)

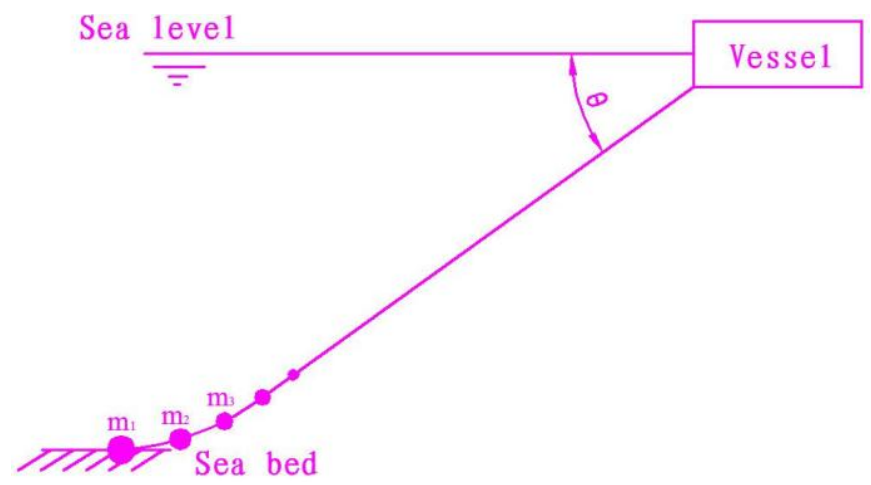

Fig. 2 Hybrid mooring line with weights (HMLW)

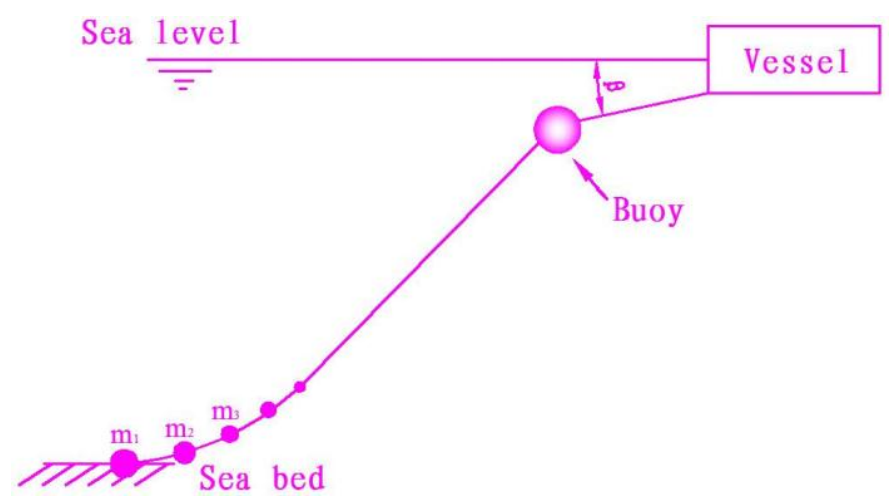

Fig. 3 Hybrid mooring line with weights and buoys

(HMLWB)

\section{EXPERIMENTS}

\section{Model}

The floating structure model used in the experiments is a 1:50 scale semi-submersible platform (Fig. 4), which is moored by the taut mooring system as well as the new hybrid mooring system. In Table 1, the main dimensions of the platform are given. The origin of the coordinate system o-xyz is shown in
Fig. 5. The horizontal x-y plane is set on the base line with its origin placed on the center of the body, and zaxis is positive upward.

Table 1

Main dimensions of the model

\begin{tabular}{ll}
\hline Length (m) & 2.28 \\
Breadth (m) & 1.57 \\
Draft (m) & 0.32 \\
Displacement (kg) & 376 \\
Transverse distance of column (m) & 1.17 \\
Longitudinal distance of column (m) & 1.17 \\
Distance between pontoons (m) & 1.17 \\
Vertical position of CG (above BL) (m) & 0.52 \\
Longitudinal coordinate of CG & 0 \\
(forward midship) (m) & 0.62 \\
Radius of inertia for pitch (m) & \\
\hline CG, centre of gravity; BL, base line
\end{tabular}

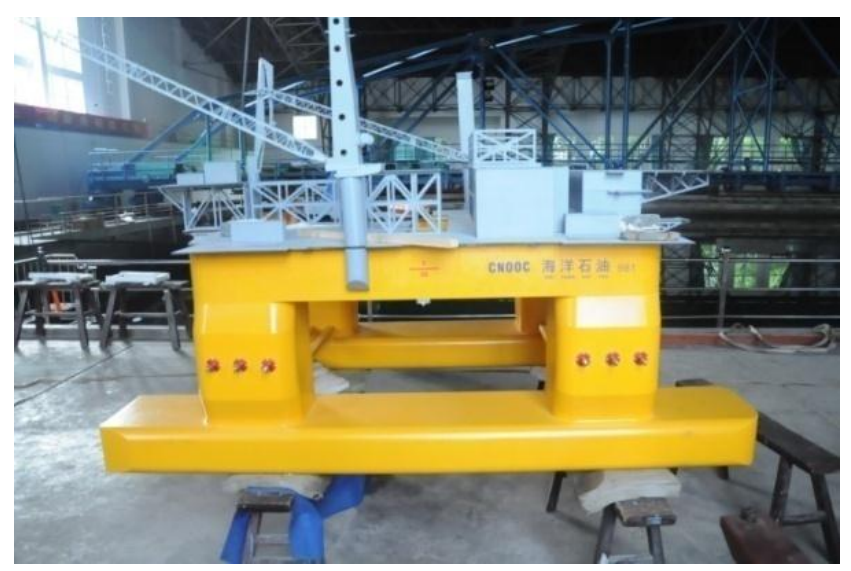

Fig. 4 Semi-submersible platform model

The semi-submersible platform is moored by three different mooring systems: taut mooring system (TMS), hybrid mooring system with weights (HMSW) and hybrid mooring system with weights and buoys (HMSWB). The latter two systems can be classified as the hybrid mooring system (HMS). The only difference between TMS and HMS should be the weights and buoys as shown in Figs. 1-3. The arrangement of the mooring lines is shown in Fig. 5, and Table 2 gives the physical properties of the mooring lines. 


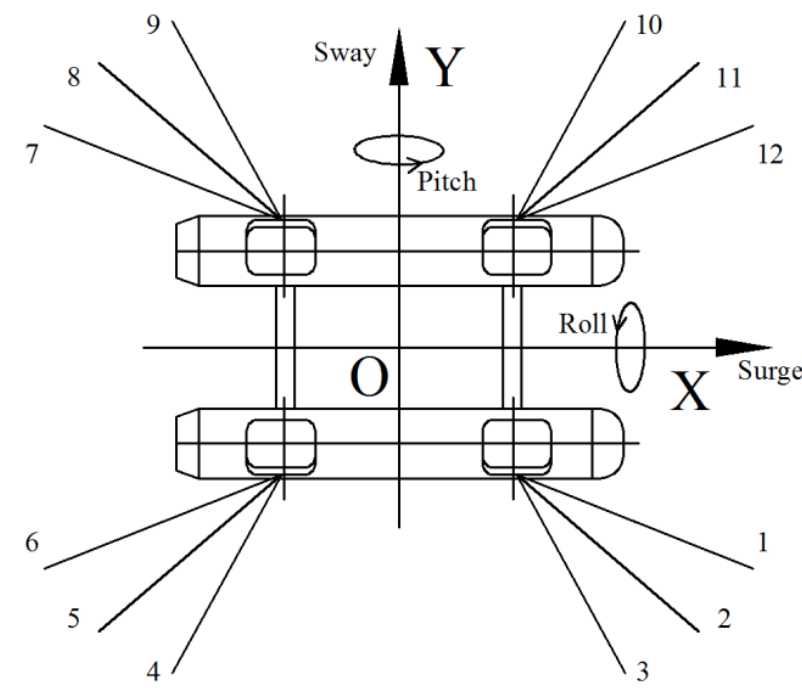

Fig. 5 Arrangement of the mooring system

\section{Table 2}

Physical properties of the mooring lines

\begin{tabular}{lrr}
\hline Length $(\mathrm{m})$ & 6.8 \\
Diameter $(\mathrm{mm})$ & 6 \\
Axial stiffness $(\mathrm{N})$ & 430 \\
Wet Weight $(\mathrm{N} / \mathrm{m})$ & 1.76 \\
Pretension $(\mathrm{N})$ & 16.98 \\
Coordinate of fairlead 1 (m) & $(0.7,-0.77,0.37)$ \\
Coordinate of fairlead 2 (m) & $(0.6,-0.77,0.37)$ \\
Coordinate of fairlead 3 (m) & $(0.51,-0.77,0.37)$ \\
& TML & 5.67 \\
Mooring radius (m) & HMLW & 5.46 \\
& HMLWB & 5.53 \\
\hline
\end{tabular}

TML: Taut mooring line

HMLW: Hybrid mooring line with weights

HMLWB: Hybrid mooring line with weights and buoys

For the hybrid mooring system, five weights are attached at the lower end of each mooring line with a uniform spacing of $0.4 \mathrm{~m}$ (Fig. 6). The size of the weights diminishes from the bottom upwards, where $m_{1}=320 \mathrm{~g}, \quad m_{2}=240 \mathrm{~g}, \quad m_{3}=160 \mathrm{~g}, m_{4}=80 \mathrm{~g}$, $m_{5}=32 \mathrm{~g}$. The buoys on each mooring line are designed to be cylinders attached $0.8 \mathrm{~m}$ away from the fairleads. The buoyancy provided by each buoy is $1.53 \mathrm{~N}$. The angle between the mooring lines and water plane is $35.2^{\circ}, 36.2^{\circ}$ and $35.9^{\circ}$ respectively for TMS, TMSW and TMSWB.

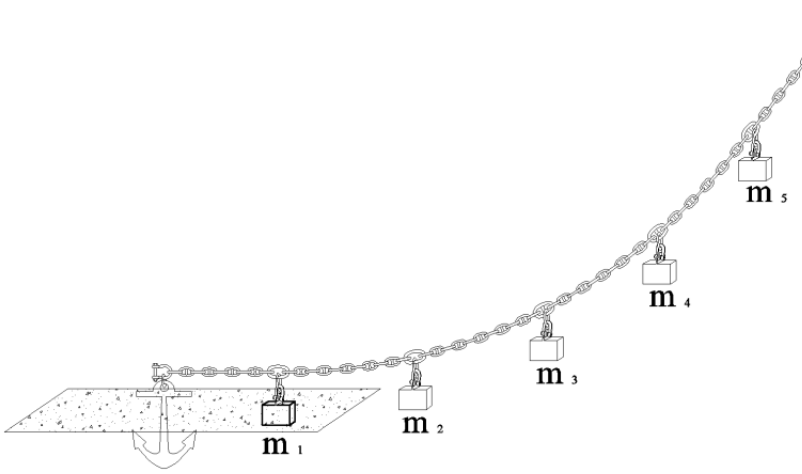

Fig. 6 Schematic of the weights

\section{Equivalent water depth truncated mooring system}

The model tests have been carried out at China Ship Scientific Research Center (CSSRC) wave basin, which is $69 \mathrm{~m}$ long, $46 \mathrm{~m}$ wide and $4 \mathrm{~m}$ deep. The water depth of the real platform is $1000 \mathrm{~m}$, which means that the water depth for the model test should be $20 \mathrm{~m}$ for the scale of $1: 50$. Since such a depth is impossible to realize in the wave basin utilized, the truncated hybrid model test technology has been adopted [10]. In the present study, the water depth has been truncated from $20 \mathrm{~m}$ to $4 \mathrm{~m}$, which means the truncation factor is 5 . The static and dynamic similarities should be checked before the model tests are carried out.

For the truncated mooring system, it is required that the total horizontal and vertical restoring force similar with full depth mooring system and the representative individual line tension characteristics are similar with full depth mooring line. There are mainly two methods for the design of equivalent water depth truncated mooring system, which are optimization method and empirical formula method. Optimization method is regarded as a fast and effective method. However, the optimization algorithm needs an enormous computational time, and it is not easy to be grasped. The empirical formula method is easier compared to the optimization method. Therefore, it is widely used recently. When it comes to largely-truncated water model tests, the equivalent water depth truncated mooring system is more suitable for its easily conducted characteristics. In the present model, the full depth mooring lines are composed by three typical kinds of segment: chain-wire-chain. The characteristics of full depth mooring line are adjusted as 
$q=\frac{q_{1} L_{1}+q_{2} L_{2}+q_{3} L_{3}}{L}$

$$
E A=\frac{L E A_{1} E A_{2} E A_{3}}{L_{1} E A_{1} E A_{3}+L_{2} E A_{1} E A_{3}+L_{3} E A_{1} E A_{2}}
$$

where $q$ is the per unit length weight in water, $L$ is the length of the segment, $E A$ is the axial stiffness of the segment, the subscripts $1,2,3$ represent top, middle and bottom segment respectively. The initial characteristics of homogeneous truncated system then can be obtained:

$L_{t}=L / \gamma_{v}$

$q_{t}=q / \gamma^{\frac{3}{4}}$

$$
E A_{t}=E A / \gamma_{v}
$$

Where, subscript $t$ represents truncated system, $\gamma_{v}$ is the water truncated factor. The final characteristics of homogeneous truncated mooring line then can be obtained with iteration method. For the new mooring lines, the lumped masses and buoys will change the per unit length weight in water, which will result in different characteristics of the truncated mooring lines. Fig. 7 shows the static design results.

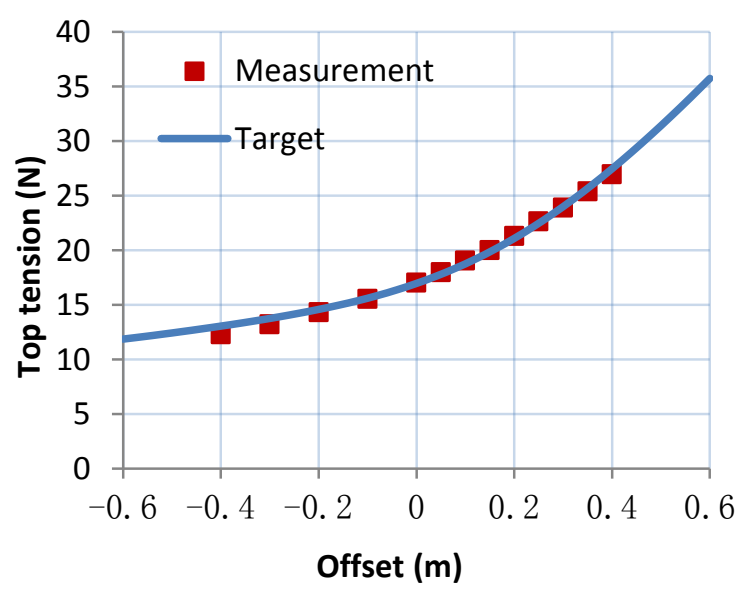

(a) Top tension of TMS

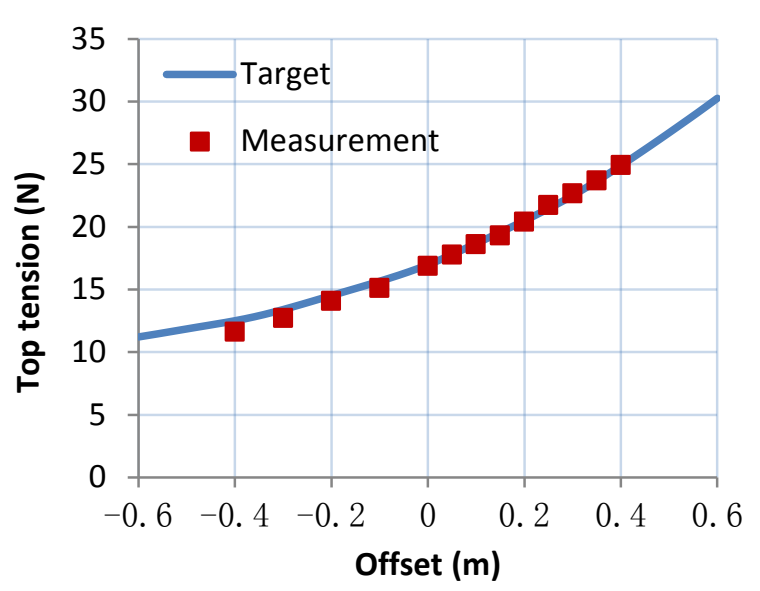

(b) Top tension of TMSW

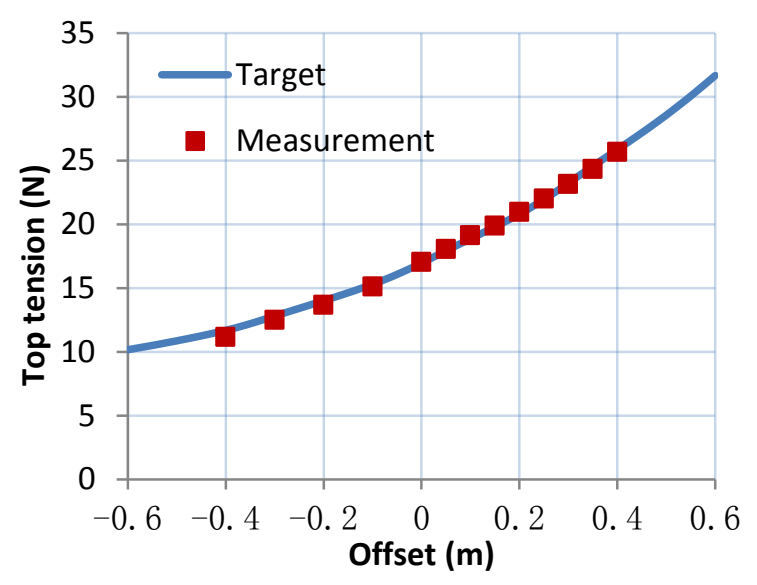

(c) Top tension of TMSWB

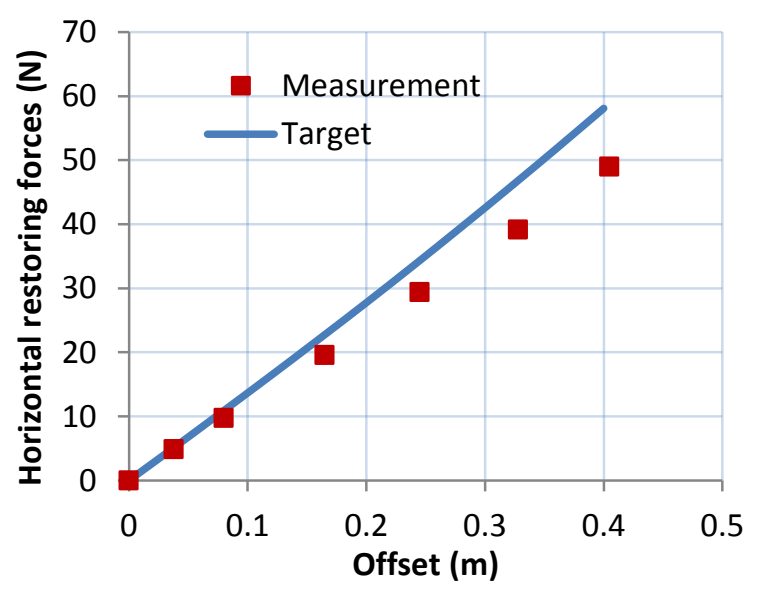

(d) Horizontal restoring force of TMS 


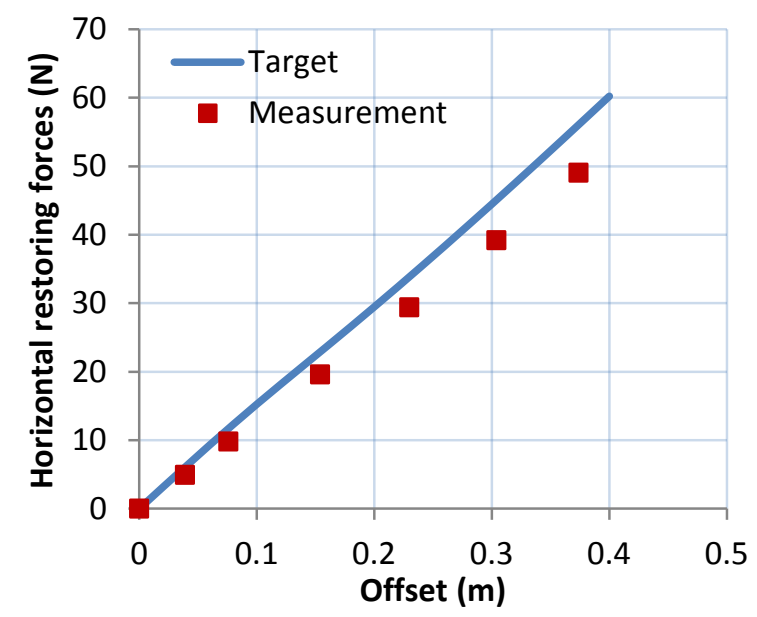

(e) Horizontal restoring force of TMSW

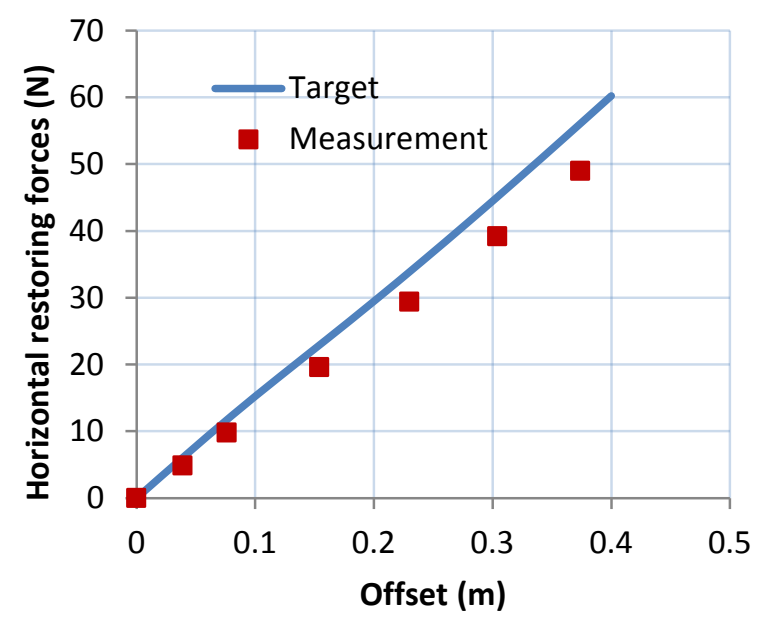

(f) Horizontal restoring force of TMSWB

Fig. 7 Static design results

It can be seen from Figs. 7 (a)-(c) that the measurements of the top tension of each truncated mooring line have very good agreement with that of target calculation, which illustrates that the truncated mooring line models are made accurately. In Figs. 7 (d)-(e), although there are some small differences between the results obtained from model tests and numerical calculation, the general trends are coinciding with each other. The dynamics of the full water depth mooring lines are always underestimated by truncated mooring lines which will result in differences of platform motion responses. In order to eliminate the dynamic differences between truncated and full depth system, a further dynamic design to truncated mooring line is necessary. The dynamic similarity can be achieved by enlarging the weight per unit length in air and the diameter of the truncated mooring lines under the preconditions that the weight per unit length in water is constant, which is important to ensure the static equivalent. The mass and the diameter will stop adjusting until the dynamic responses of the truncated system are close to that of full depth system. Fig. 8 is the free decay test results of surge motion, from which we can find the natural period and damping ratio of these three types of mooring systems are close to each other.

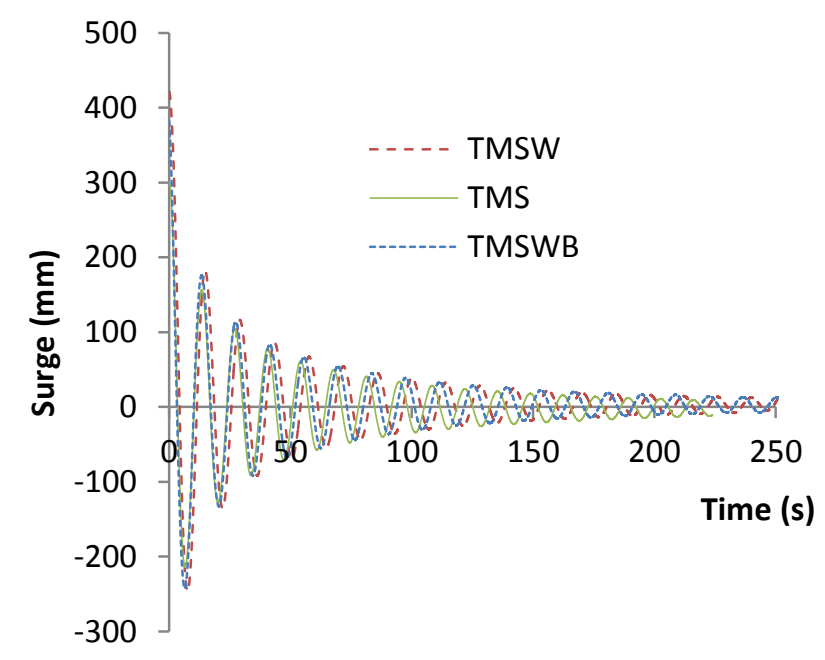

Fig. 8 Free decay test

\section{Experimental program}

The experimental program consists of a series of model tests in irregular waves. The wave heading angles consist of $180^{\circ}$ (head sea), $135^{\circ}$ (oblique sea), and $90^{\circ}$ (beam sea). For the loading condition, the 100-year extreme hurricane condition at the South China Sea is used, known as one of the severest in the world. The corresponding wave properties in the model scale are the significant wave height of $0.274 \mathrm{~m}$, the peak period of $2.26 \mathrm{sec}$ and the peak enhancement factor of 2.4. The target and measurement of the JONSWAP spectra is shown in Fig. 10.

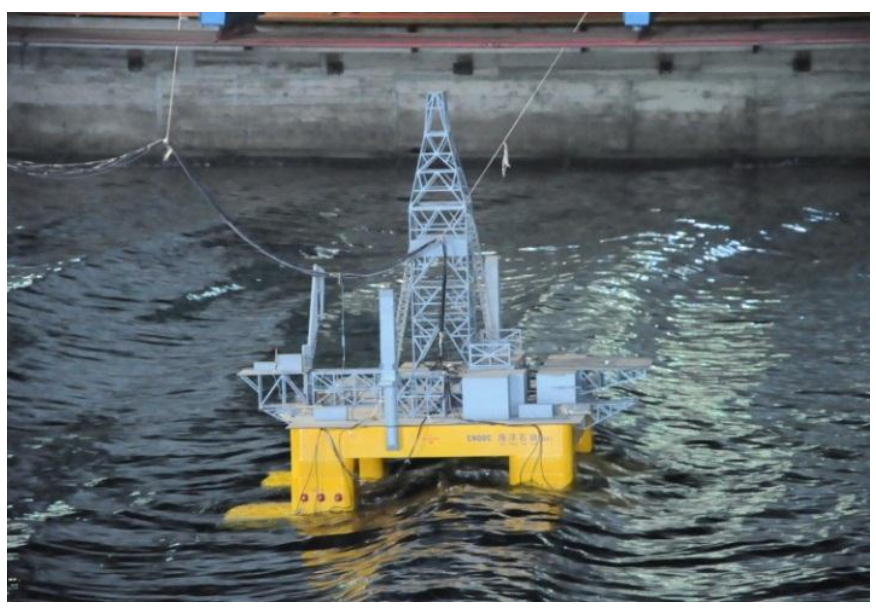

Fig. 9 Model tests in irregular waves 


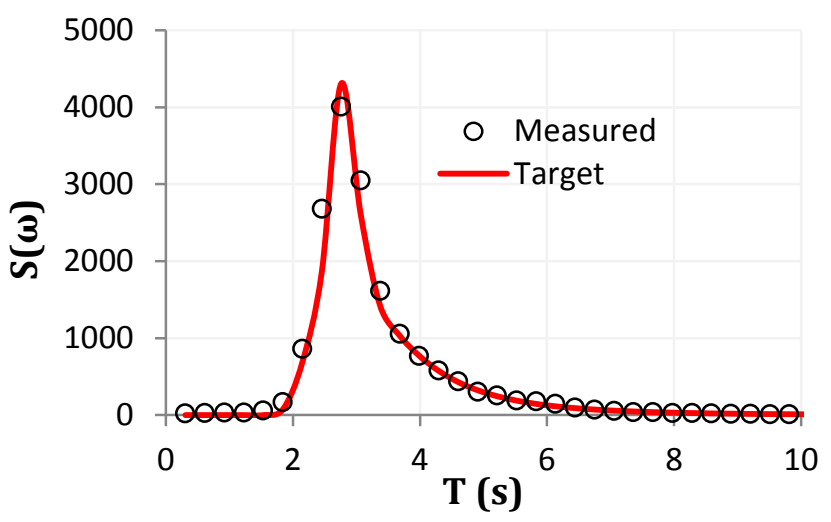

Fig. 10 Jonswap spectra

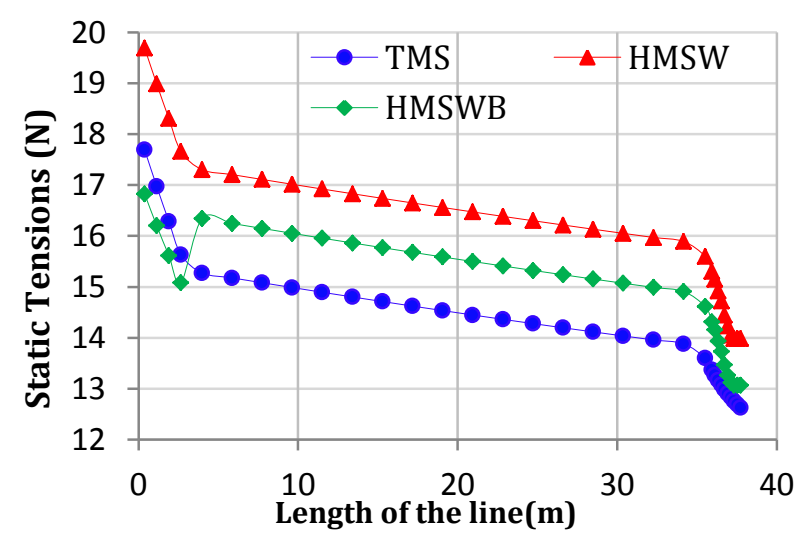

Fig. 11 Static tension on the mooring lines

In the present study, there are mainly three important items which must be recorded: motions of the model, tension on the mooring lines and movements of $m_{1}$. Fig. 9 shows the model tests in the irregular waves. In the head sea case (heading angle is $180^{\circ}$ ), surge, heave and pitch motions are measured; in the oblique wave case (heading angle is $135^{\circ}$ ), 6-DOF motions are measured; in the beam sea case (heading angle is $90^{\circ}$ ), only sway, heave and roll motions are measured. All the motions are measured by a Non-contact Test System of 6D Motions. Meanwhile, the tension sensors are used to measure to the tension on the mooring lines. Fig. 11 shows the real model simulation results of the static tension along the mooring lines. It can be found that the static tension decreases downwards, and the tension on the top end of the lines is the maximum value. Therefore, 12 sensors have been arranged at the top end on each mooring line to measure the dynamic tension. However, in the present study, only the dynamic tension on mooring line No.3 will be presented. The movements of the first lumped mass $m_{1}$ have been recorded by an underwater camera to check if there is any vertical force on the lower end of the mooring lines.

\section{Experimental results and discussion}

The duration of the tests is around 1800s, which corresponds to 3.5 hours for the full scale model. The sampling frequency is fixed at 0.02s. All the data collected from TMS and HMSW is valid. Unfortunately, some data (from 550s to 750s) collected from beam sea case for HMSWB is invalid due to the problem of wave maker. To make the statistical variability reliable, we remove these data and present a consistent duration of 900 s that contains the maximum values of the responses. However, the statistical variability is based on all the valid data.

\section{(1) Beam sea case (heading angle is $90^{\circ}$ )}

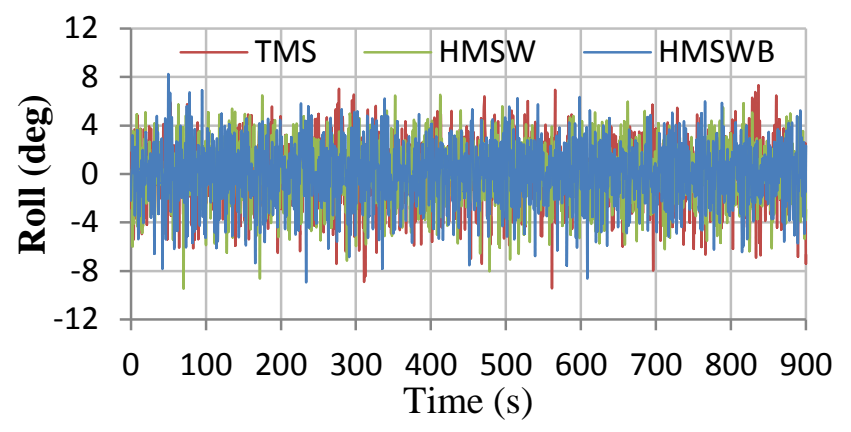

Fig. 12 (a) Time history of roll $\left(90^{\circ}\right)$

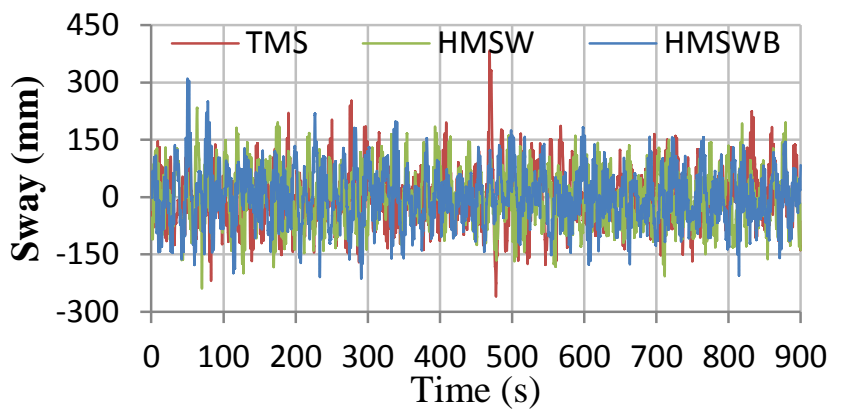

Fig. 12 (b) Time history of sway $\left(90^{\circ}\right)$

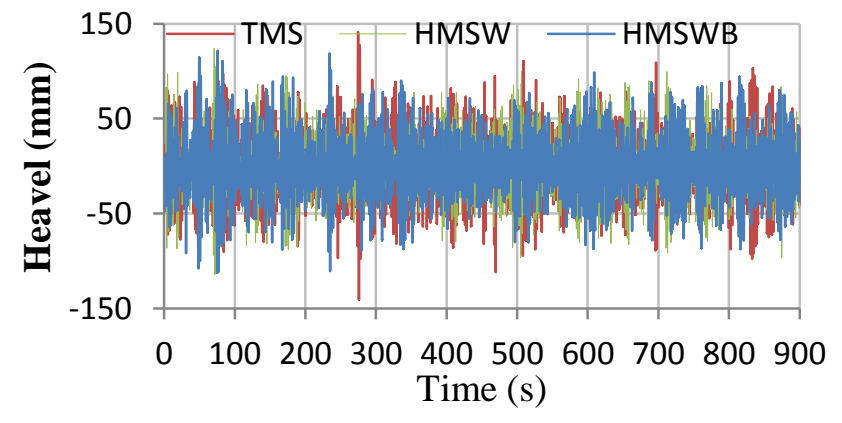

Fig. 12 (c) Time history of heave $\left(90^{\circ}\right)$ 
Table 3

Motions of the model (Beam sea)

\begin{tabular}{llrrr}
\hline & & TMS & HMSW & HMSWB \\
Roll (deg) & MAX & 9.45 & 9.47 & 8.94 \\
& SD & 2.29 & 2.19 & 2.27 \\
Sway(mm) & MAX & 383.2 & 239.1 & 310 \\
& SD & 71.09 & 67.28 & 69.64 \\
Heave(mm) & MAX & 141.4 & 124 & 121.7 \\
& SD & 33.66 & 31.79 & 32.55 \\
\hline
\end{tabular}

MAX: maximum value; SD: standard deviations

The time series of sway, heave and roll motion of the platform moored by TMS, HMSW and HMSWB in beam sea condition are shown in Fig. 12. Table 3 gives the statistical variability of the maximum values and standard deviations of the motion responses. It can be found that comparing to TMS, the standard deviations of motion responses can be reduced slightly by using HMSW. The reduction of standard deviations from HMSWB is even more unremarkable. But HMSWB can reduce the maximum values of the response in beam sea case.

By using Fast Fourier Transform (FFT), the motion spectra of the platform can be obtained and plotted in Fig. 13. Overall, the shapes of the three spectrums are similar and the difference of peak values is not remarkable. The sway motion is dominated by low frequency (LF) responses, while wave frequency (WF) responses are the most important part for heave motion. But from Fig. 13 (a) we can find that both low frequency and wave frequency responses are important for roll motion. In the low frequency range, the peak value of HMSW is the largest one of all. But in the wave frequency range, it becomes the smallest one. The difference between TMS and HMSWB is quite small.

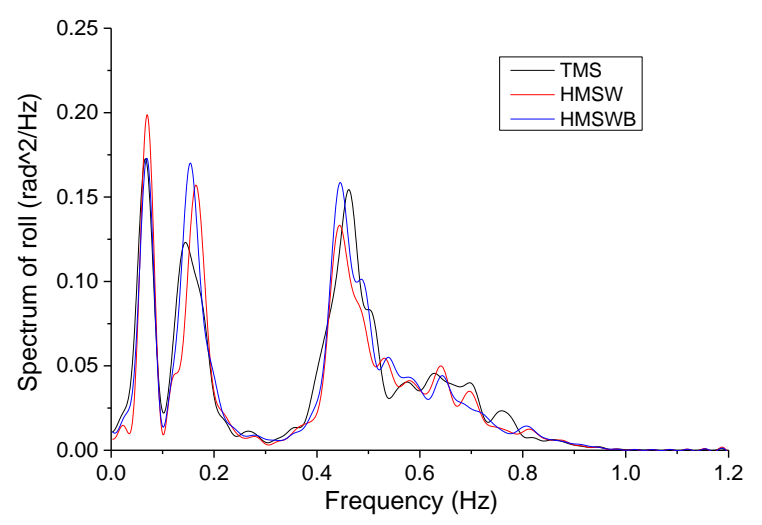

Fig. 13 (a) Spectral density of roll $\left(90^{\circ}\right)$

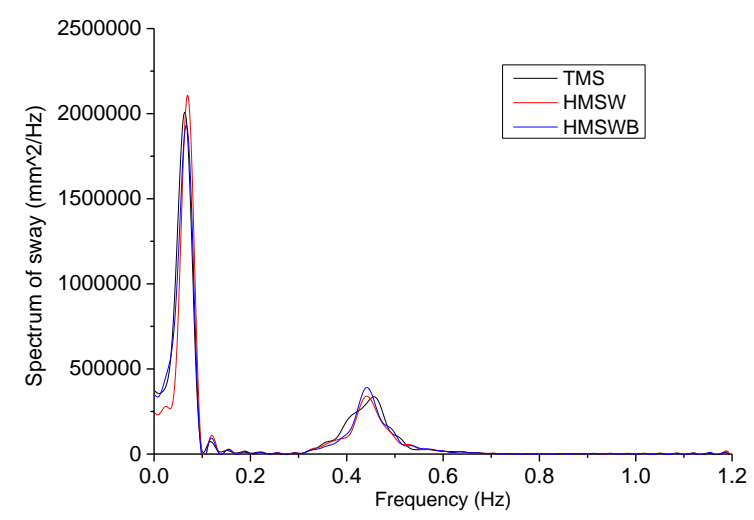

Fig. 13 (b) Spectral density of sway $\left(90^{\circ}\right)$

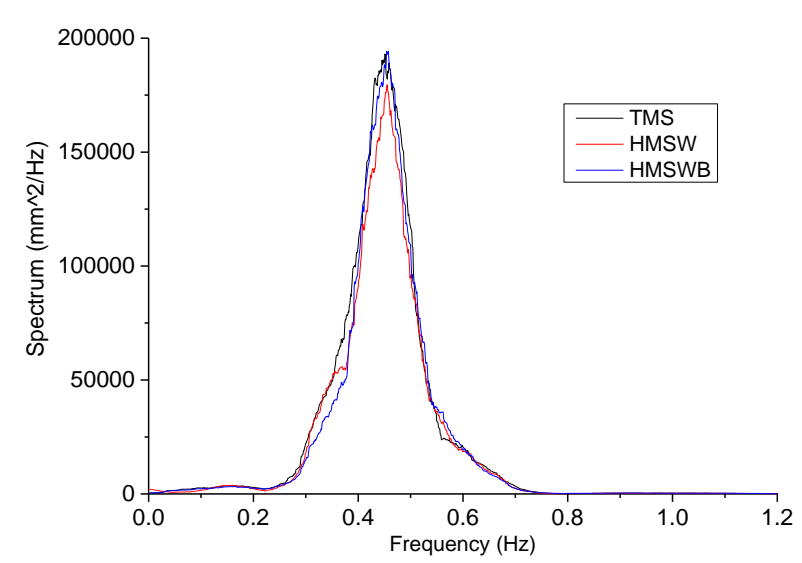

Fig. 13 (c) Spectral density of heave $\left(90^{\circ}\right)$

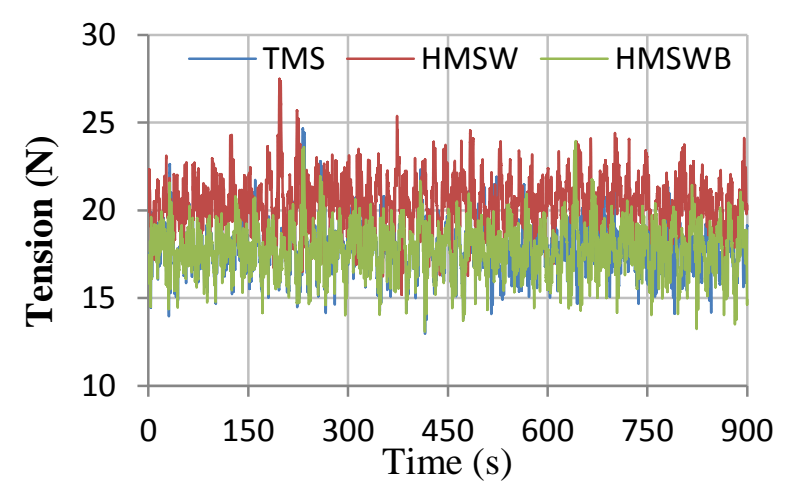

Fig. 14 Dynamic tension $\left(90^{\circ}\right)$

Table 4

Tension on the mooring lines (Beam sea) (unit: N)

\begin{tabular}{|c|c|c|c|}
\hline & TMS & HMSW & HMSWB \\
\hline MEAN & 17.87 & 20.42 & 17.80 \\
\hline MAX & 24.67 & 27.50 & 23.95 \\
\hline SD & 1.34 & 1.42 & 1.34 \\
\hline
\end{tabular}

Fig. 14 shows the dynamic top tension on Line No. 3 . Table 4 gives the statistical variability of the standard deviations, the maximum and mean values of the motion responses. We find that the top tension on the lines could be increased by using HMSW, since the weights will increase the stiffness of the lines. The mean values and standard deviations of top tension of HMSW are 14\% and 6\% 
larger than that of TMS respectively. But the difference of top tension between HMSWB and TMS is quite small. Fig. 15 is the tension spectrum results. Consistent with the time history results, the tension spectrum of HMSWB is quite close to each other. It can also be observed that the low frequency tensions take the dominate part. In the low frequency range, the peak value of tension spectrum of HMSW is the largest one of all. But when it comes to the wave frequency range, the difference between these three mooring system is very small.

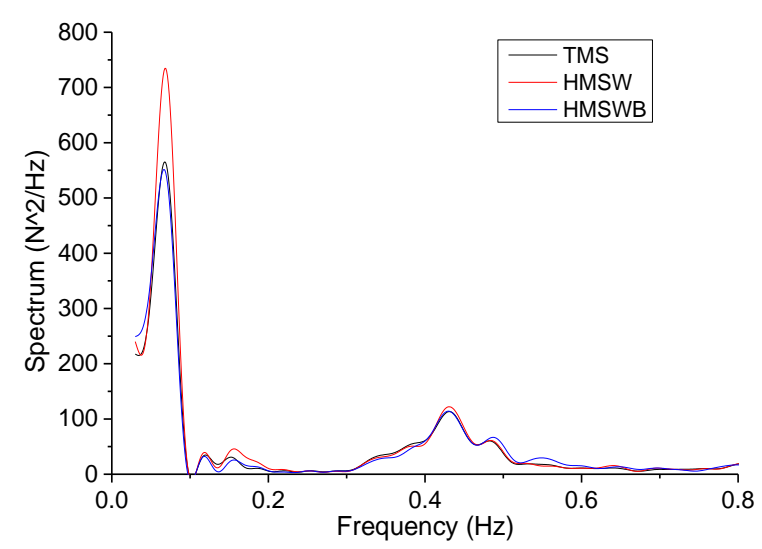

Fig. 15 Spectral density of tension $\left(180^{\circ}\right)$

\section{(2) Oblique wave case (heading angle is $135^{\circ}$ )}

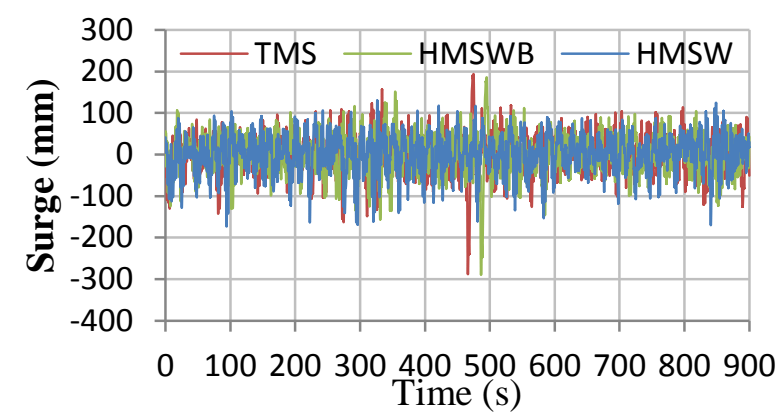

Fig. 16 (a) Time history of surge $\left(135^{\circ}\right)$

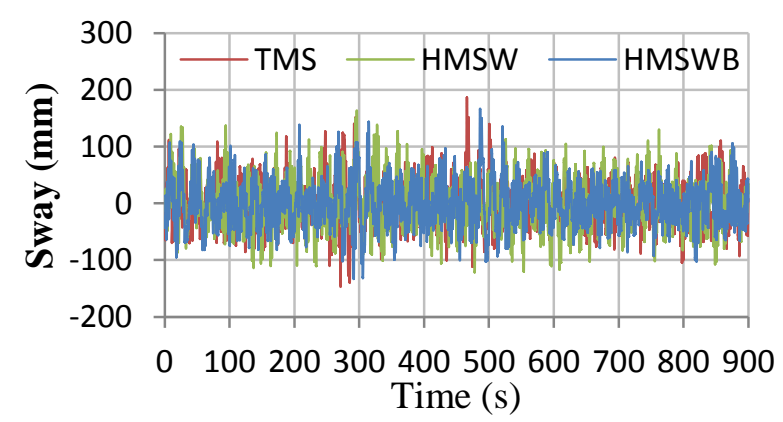

Fig. 16 (b) Time history of sway $\left(135^{\circ}\right)$

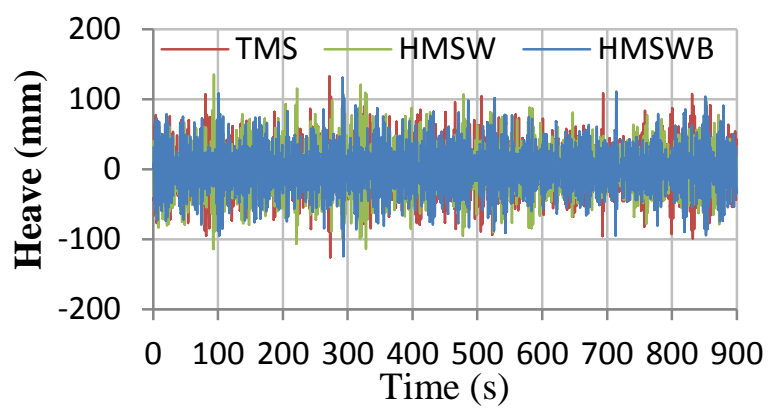

Fig. 16 (c) Time history of heave $\left(135^{\circ}\right)$

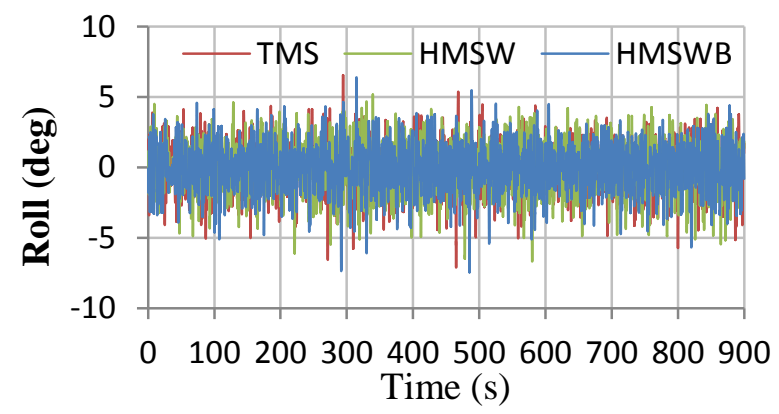

Fig. 16 (d) Time history of roll $\left(135^{\circ}\right)$

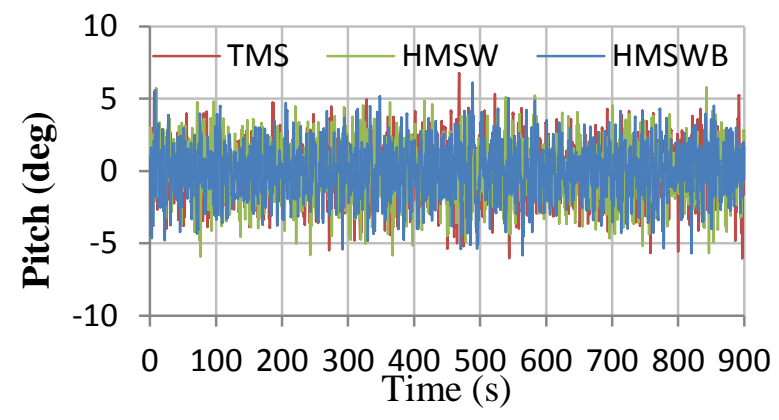

Fig. 16 (e) Time history of pitch $\left(135^{\circ}\right)$

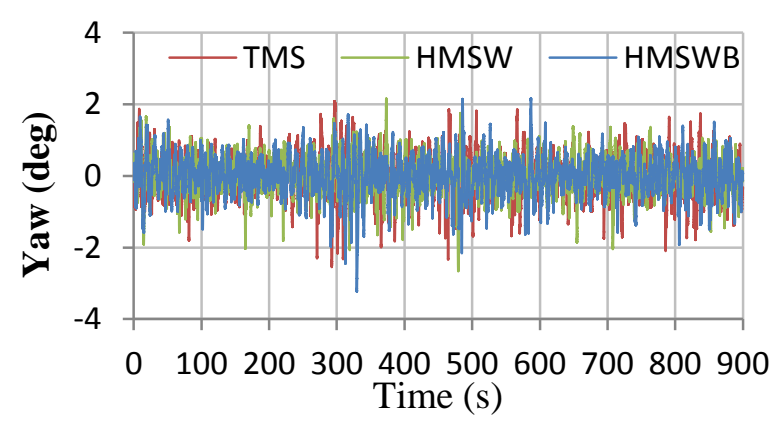

Fig. 16 (f) Time history of yaw $\left(135^{\circ}\right)$

Table 5

Motions of the model (Oblique wave)

\begin{tabular}{llrrr}
\hline & & TMS & HMSW & HMSWB \\
Surge(mm) & MAX & 287.7 & 173.3 & 289.6 \\
& SD & 46.5 & 45.8 & 46.1 \\
Sway(mm) & MAX & 186.3 & 163.7 & 166.5 \\
& SD & 39.3 & 43.2 & 39.3 \\
Heave(mm) & MAX & 133.1 & 135.4 & 130.7 \\
& SD & 31.8 & 32.4 & 31.7 \\
Roll(deg) & MAX & 7.11 & 6.69 & 7.45 \\
Pitch(deg) & SD & 1.59 & 1.69 & 1.6 \\
& MAX & 6.76 & 5.92 & 6.1
\end{tabular}




\begin{tabular}{lllll} 
& SD & 1.74 & 1.79 & 1.73 \\
\multirow{2}{*}{ Yaw(deg) } & MAX & 2.54 & 2.66 & 3.24 \\
& SD & 0.63 & 0.52 & 0.57 \\
\hline
\end{tabular}

MAX: maximum value; SD: standard deviations

Fig. 16 shows the time history of the motions of the model in the oblique wave case. Table 5 gives the statistical variability of the standard deviations, the maximum and mean values of the motion responses. It can be stated that the standard deviations of sway, heave, roll and pitch are increased by using HMSW. But in surge and yaw motion, HMSW can bring a small reduction. The difference of the standard deviations between HMSWB and TMS is quite small. This is consistent with the spectral analysis results from Fig. 17. The low frequency responses take the major part in the horizontal motions, including surge, sway and yaw, which can be seen from Figs. 17 (a) (b) (f). From Fig. 17 (a) we find that the surge spectrums are quite close to each other for all of the mooring systems. Discrepancies can be observed from Fig. 17 (b) of sway spectrums. The peak values of HMSW are larger than those of the other two mooring systems in both low frequency and wave frequency range. But the low frequency yaw motion of HMSW is the smallest one. Wave frequency responses take the dominate place in heave motion and the difference between these three mooring systems is not remarkable, which can be seen from Fig. 17 (c). From Figs. 17 (d) (e) we can find that both low frequency and wave frequency responses are important for roll and pitch motion. Larger peak values can be observed by using HMSW, while the different between TMS and HMSWB is not noticeable.

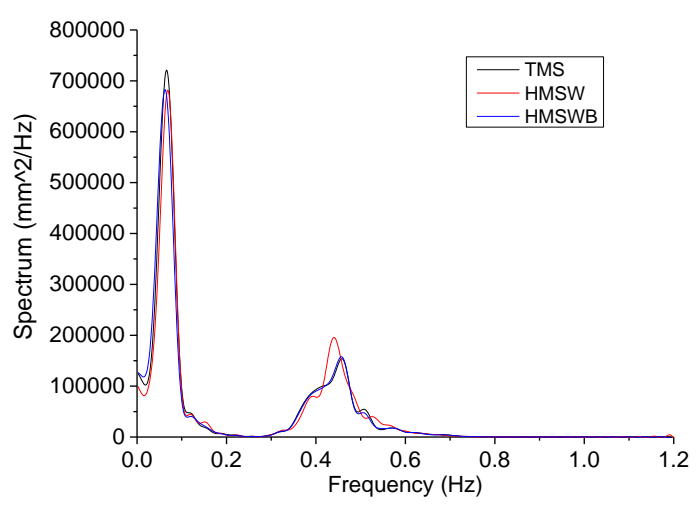

Fig. 17 (a) Spectral density of surge $\left(135^{\circ}\right)$

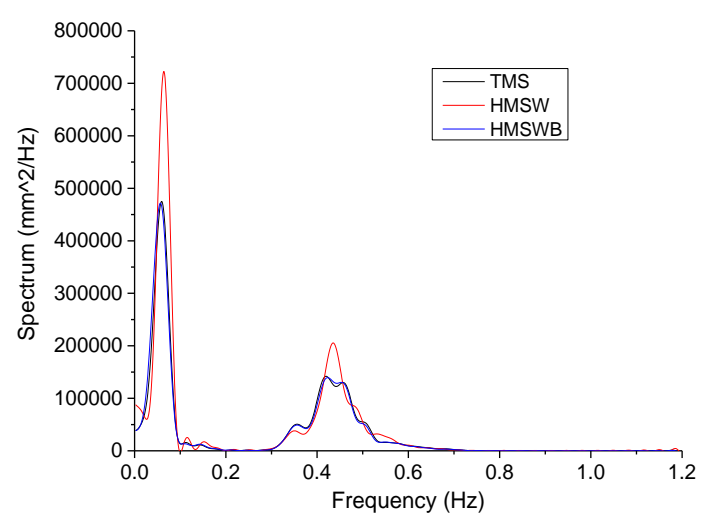

Fig. 17 (b) Spectral density of sway $\left(135^{\circ}\right)$

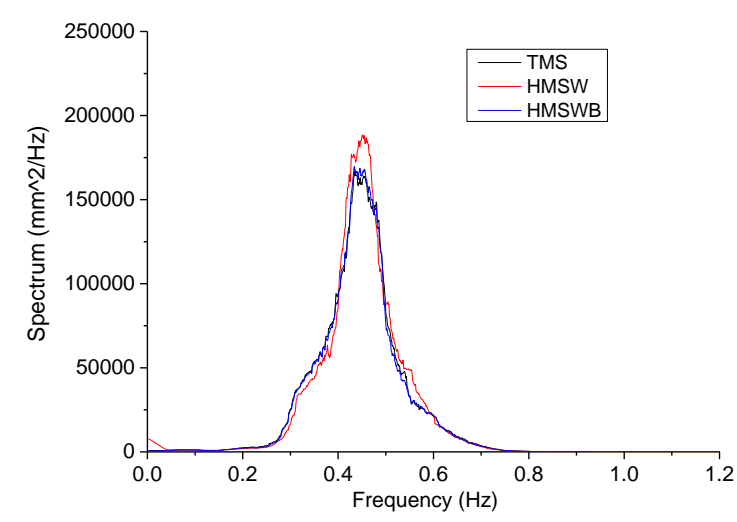

Fig. 17 (c) Spectral density of heave $\left(135^{\circ}\right)$

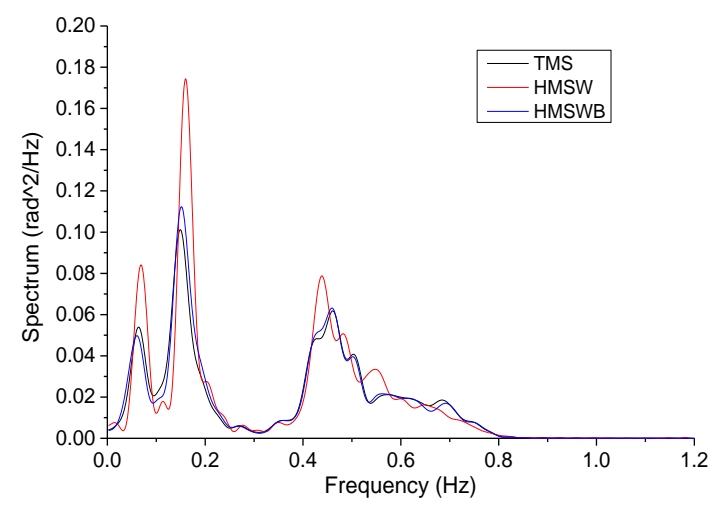

Fig. 17 (d) Spectral density of roll $\left(135^{\circ}\right)$

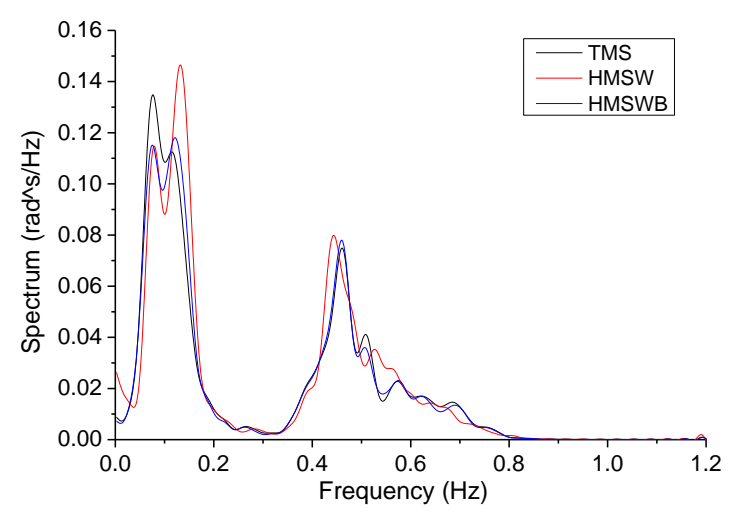

Fig. 17 (e) Spectral density of pitch $\left(135^{\circ}\right)$ 


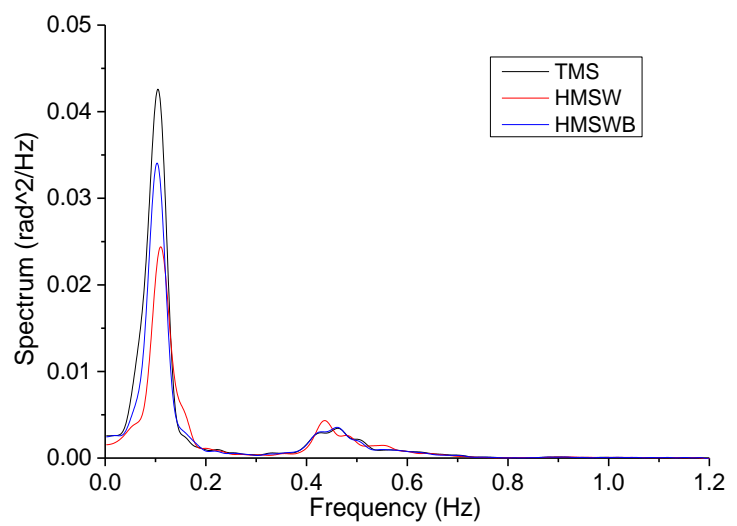

Fig. 17 (f) Spectral density of yaw $\left(135^{\circ}\right)$

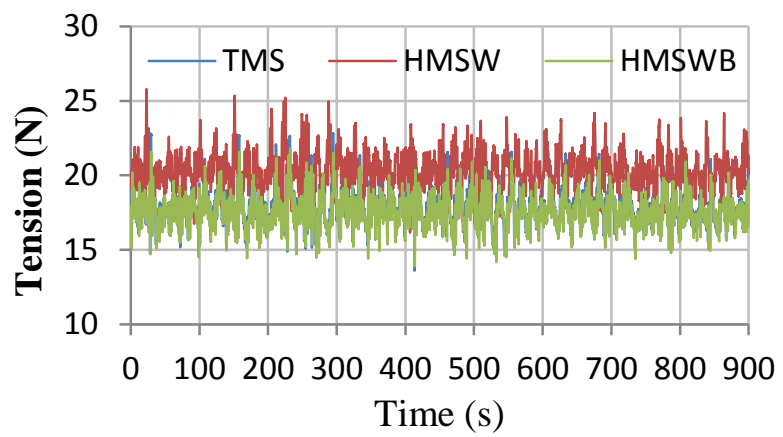

Fig. 18 Dynamic tension $\left(135^{\circ}\right)$

Table 6

Tension on the mooring lines (Oblique wave) $(\mathrm{N})$

\begin{tabular}{lccc}
\hline & TMS & HMSW & HMSWB \\
MEAN & 17.89 & 20.34 & 17.59 \\
MAX & 22.82 & 25.76 & 21.76 \\
SD & 1.18 & 1.2 & 1.09 \\
\hline
\end{tabular}

MAX: maximum value; SD: standard deviations

The dynamic top tension in oblique wave is shown in Fig. 18 and Table 6 gives the statistical variability of the standard deviations, the maximum and mean values of the motion responses. The top tension of the lines in oblique wave is consistent with that in beam sea condition. The mean values and standard deviations of HMSWB are slightly less than that of TMS. But HMSW will bring a growth to the top tension on the mooring lines.

\section{(3) Head sea case (heading angle is $180^{\circ}$ )}

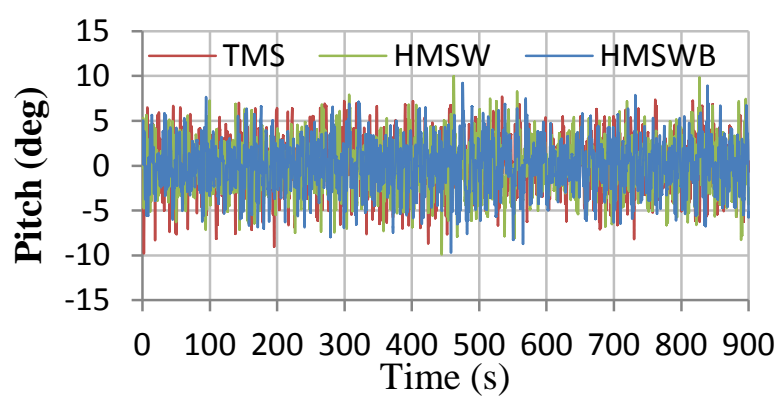

Fig. 19 (a) Time history of pitch $\left(180^{\circ}\right)$

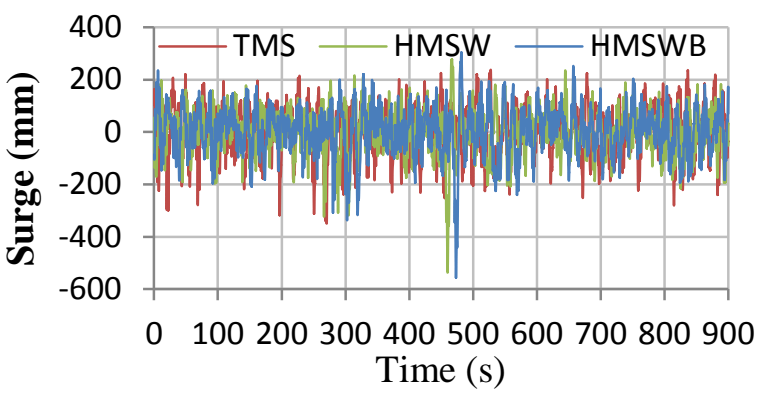

Fig. 19 (b) Time history of surge $\left(180^{\circ}\right)$

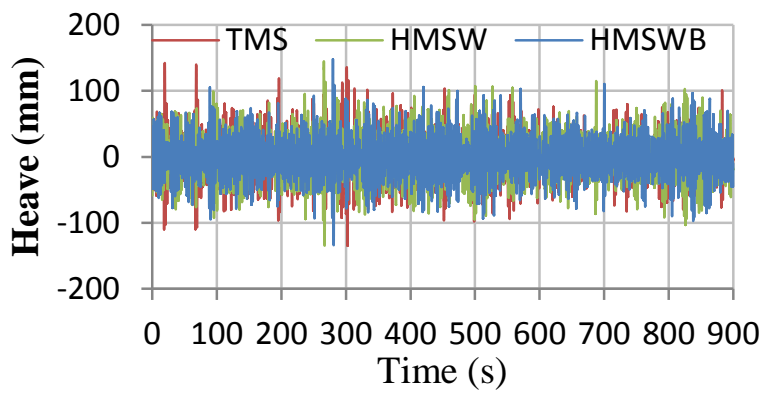

Fig. 19 (c) Time history of heave $\left(180^{\circ}\right)$

Table 7

Motions of the model (Head sea)

\begin{tabular}{clrrr}
\hline & & TMS & HMSW & HMSWB \\
Pitch(deg) & MAX & 9.8 & 10.0 & 9.7 \\
& SD & 2.8 & 2.7 & 2.7 \\
Surge(mm) & Max & 349.7 & 536.9 & 556.5 \\
& SD & 95.2 & 85.8 & 91.8 \\
Heave(mm) & Max & 142.2 & 144.7 & 147.8 \\
& SD & 33.3 & 32.9 & 32.0 \\
\hline
\end{tabular}

MAX: maximum value; SD: standard deviations

From the motion responses results in Fig. 19 and Table.7 we can find that in head sea condition, the motion responses can be reduced by using either hybrid mooring systems. The reduction in pitch and heave is not remarkable, which is consistent with the response spectra in Figs. 20 (a) (c). But for surge motion, a noticeable decrease can be observed by using HMSW. This could also be found from the surge spectrum in Fig. 20 (b). In head sea case, the low frequency responses are the major part and the hybrid mooring system can reduce the peak values of surge motion in low frequency range. 


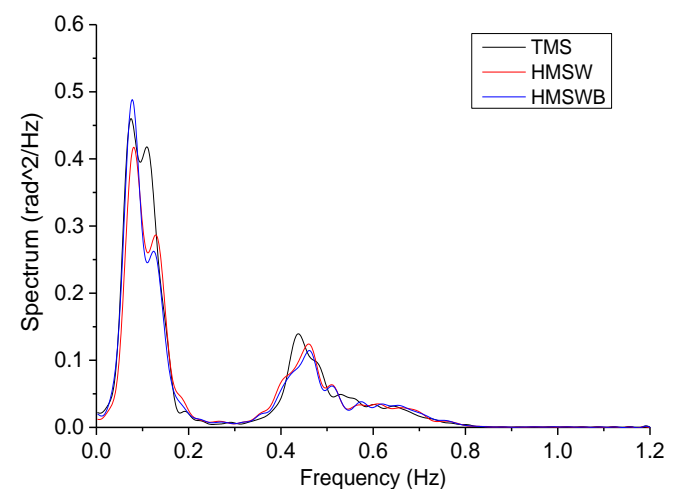

Fig. 20(a) Spectral density of pitch $\left(90^{\circ}\right)$

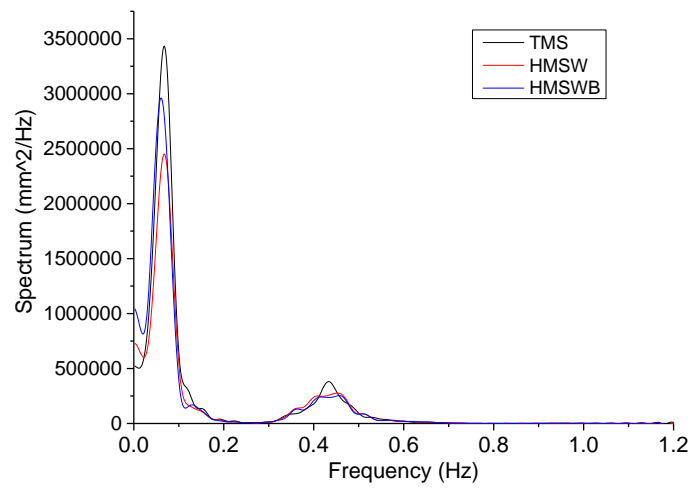

Fig. 20(b) Spectral density of surge $\left(90^{\circ}\right)$

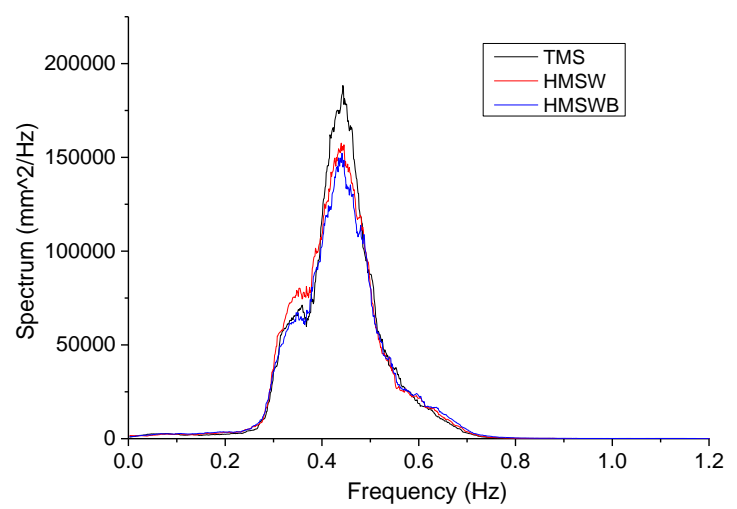

Fig. 20(c) Spectral density of heave $\left(90^{\circ}\right)$

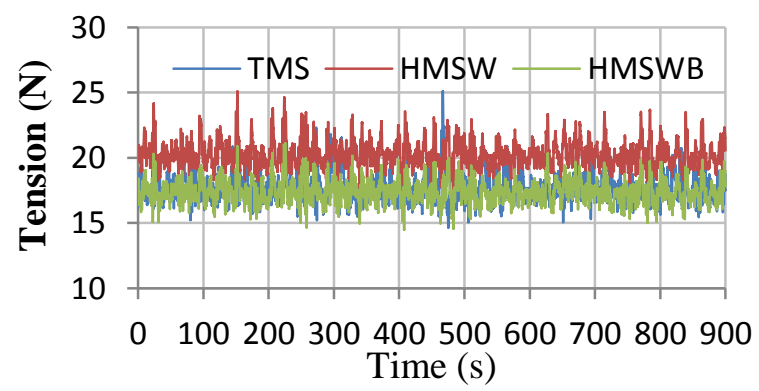

Fig. 21 Dynamic tension $\left(90^{\circ}\right)$

Table 8

Tension on the mooring lines (Heam Sea) (unit: N)

\begin{tabular}{lccc}
\hline & TMS & HMSW & HMSWB \\
MEAN & 17.72 & 20.29 & 17.41 \\
MAX & 25.1 & 25.1 & 21.1 \\
SD & 0.99 & 1.0 & 0.88 \\
\hline
\end{tabular}

MAX: maximum value; SD: standard deviations
Fig. 21 and Table 8 are the dynamic top tension results Line No. 3 in head sea condition. It is consistent with the beam sea and oblique wave cases. The use of HMSW will increase the mean values of top tension on the mooring lines. But the difference of standard deviations between HMSW and TMS is quite small. The mean values and standard deviations of HMSWB are slightly less than that of TMS.

\section{(4) Movements of $m_{1}$}

Particular attention should be paid to the vertical movements of the weight $m_{1}$, since it will decide which kind of anchor should be used.

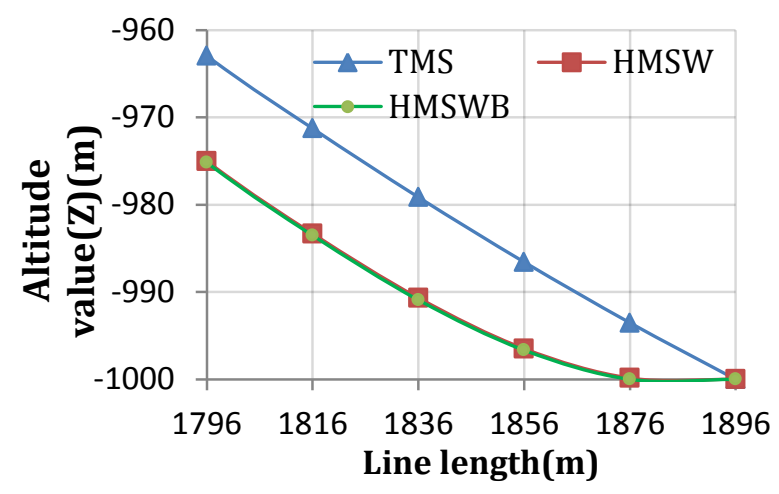

Fig. 22 Altitude values (Beam sea)

Fig. 22 is the real model numerical simulation results of the altitude values at each node in the lower end of the mooring lines when the lines are subject to the maximum dynamic tension. The position of $m_{2}$ and $m_{1}$ corresponds to the line length at $1856 \mathrm{~m}$ and $1876 \mathrm{~m}$ respectively, and $1896 \mathrm{~m}$ corresponds to the anchor point. It can be found in the numerical simulation that $m_{1}$ always lies in the sea floor when HMSW and HMSWB are used, while $m_{2}$ can be lifted by a small value. But if there is no weight attached to the mooring lines, the lower end of the line behaves just like a straight line.

In the model tests, it is impossible to measure the motion of each weight. But the movements can be recorded by the underwater camera. Fig. 23 is a screenshot from the video. From all the recorded videos in different wave heading angles, $m_{1}$ lies horizontally in the sea floor all the time even when the lines are subject to the maximum tension. It can also be illustrated that there is no vertical force at the anchor point, which means that a drag embedment anchor can be used in the new hybrid mooring system. 


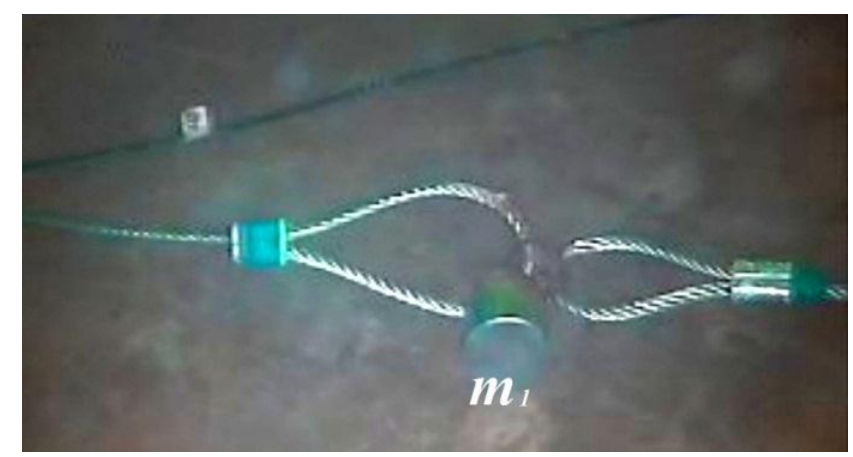

Fig. 23 Screenshot from the video record

\section{Conclusions}

In the present study, two new hybrid mooring systems are proposed. A series of model tests were carried out to verify the effectiveness of these hybrid mooring systems. Comparing the results of these hybrid systems to the case with taut mooring system, the following conclusions can be made:

1) Motions of the platform:

Compared to TMS, HMSW will bring some reductions to the motions of the platform in beam sea and head sea condition. In oblique wave, the motion responses of the platform are increased slightly by using HMSW. The difference of the motion responses between TMS and HMSWB is quite small.

2) Tension on the lines

Compared to TMS, the tension on the lines will be enlarged by using HMSW. However, if a buoy is attached to the mooring lines (HMSWB), the tension could be reduced.

3) Movements of $m_{1}$

From the video records of the model tests, it can be seen that the weight $m_{1}$ lies horizontally on the sea floor all the time, which means there are only horizontal forces at the anchor point, and the drag embedment anchor can be used to reduce the installation and maintenance cost.

According to the discussion above, it can be concluded that HMSWB has better performance than TMS and HMSW. The motions of the platform and the tension on the mooring lines are at the same level as TMS, but the drag embedment anchor can be used for HMSWB. It will significantly reduce the cost of installation and maintenance by using the drag embedment anchor. Meanwhile, HMSWB can be extensively applied in wide range of sea floor soil condition.

\section{Acknowledgment}

This study was supported financially by the National Natural Science and Foundation of China (Grant No. 51379095) and the National Basic Research Program of China (973 Program) (Grant No. 2013CB36100).

\section{References}

[1] Brook, A.K., 1985. The Design of Catenary Mooring Systems for Offshore Vessels. Offshore Goteborg, Gothenburg, Vol. 3.

[2] Patel, M. H., Brown, D. T., 1987. Analysis and Design of Catenary Mooring Systems. Economics of Floating Production Systems: Proceedings of an International Conference, London, UK.

[3] Johnsen, J. M., 1999. Design and Optimization of Taut-Leg Mooring Systems. Offshore Technology Conference, Houston, Texas.

[4] Del Vecchio, C.J., 1996. Taut Leg Mooring Systems Based on Polyester Fiber RopesPetrobas' Experience and Future Developments. International Conference on Mooring and Anchoring, Aberdeen, UK.

[5] Smith, R. J., MacFarlane, C. J., 2001. Statics of a three component mooring line. Ocean Engineering 28, pp.899-914.

[6] Vicente, P. C., Falcão, A. F., Justino P. J., 2011. Slack-chain mooring configuration analysis of a floating wave energy converter. 26th International Workshop on Water Waves and Floating Bodies, Athens, Greece.

[7] Hong, S. W., Kim, J. H., 2004. Experimental Study of a Compliant Mooring System for a Floating OWC Device, Proceeding of The Fourteenth International Offshore and Polar Engineering Conference, Toulon, France.

[8] Ji, C.Y., Yuan, Z.M., Chen, M.L., 2011. Study on a new mooring system integrating catenary with taut mooring. China Ocean Eng., 25(3), pp. 427-440.

[9] Yuan, Z.M., Ji, C.Y., Chen, M.L., Zhang, Y., 2011. Coupled analysis of floating structures with a new mooring system. 30th International Conference on Ocean, Offshore and Arctic Engineering, OMAE2011-49597, Rotterdam, The Netherlands.

[10] Zhang, H., Gao, W., Wang, Q., Jiang, J., Zhao, Z., 2012. Investigation on optimization 
design of an equivalent water depth truncated mooring system based on INSGAII. Journal of Marine Science and Application, 11(2), pp. 208-215. 